\title{
Effects of Communication Robot on Distress Reduction in Mammography
}

\author{
Yongbum Lee, Mieko Uchiyama, Akira Hasegawa, Rika Saitoh \\ Graduate School of Health Sciences, Niigata University, Niigata, Japan \\ Email: lee@clg.niigata-u.ac.jp
}

How to cite this paper: Lee, Y., Uchiyama, M., Hasegawa, A. and Saitoh, R. (2017) Effects of Communication Robot on Distress Reduction in Mammography. J. Biomedical Science and Engineering, 10, 107-119. https://doi.org/10.4236/jbise.2017.103009

Received: February 21, 2017

Accepted: March 20, 2017

Published: March 23, 2017

Copyright $\odot 2017$ by authors and Scientific Research Publishing Inc. This work is licensed under the Creative Commons Attribution International License (CC BY 4.0).

http://creativecommons.org/licenses/by/4.0/

(c) (i) Open Access

\begin{abstract}
Mammography is obviously useful for the early detection and diagnosis of breast diseases in women. However, it usually involves anxieties and pains. This paper aimed to explore effects of the communication robot on distress reduction in mammography. Nineteen healthy women participated in the examination. They were randomly assigned to either an experimental group $(n=9)$ or a control group $(n=10)$. The participants in the experimental group talked and played with a communication robot before mammography. PALRO (FUJISOFT Inc., Tokyo, Japan) was used as the communication robot, which was a chatty, comforting robot. PALRO can communicate with the human and has several specific applications such as dancing, singing and talking about knowledge of various things. Autonomic nervous activities were observed before and during mammography. Degrees of subjective pain associated with mammography were also assessed using a visual analogue scale (VAS). As a result, autonomic nervous activities between the experimental group and the control group were not significantly different. Unfortunately, the communication robot did not help to intensify parasympathetic nerve activities, which became dominant at rest or a relaxed state. On the other hand, the VAS scores for pain in the experimental group were significantly smaller than ones in the control group $(\mathrm{p}<0.01)$. This result suggested that the communication robot was useful for relieving degrees of subjective pain associated with mammography. In conclusion, communication with a robot before mammography would yield positive emotions and it would be related to the pain alleviation during mammography.
\end{abstract}

\section{Keywords}

Mammography, Communication Robot, Alleviation of Anxiety and Pain, Autonomic Nervous Function, Visual Analogue Scale

\section{Introduction}

Mammography is widely used for the early detection and diagnosis of breast 
diseases in women. However, breast compression and immobilization during mammography usually give a pain to the examinee [1] [2] [3] [4] [5]. In addition, the radiological technologist often directly grasps the breast and spreads it further in order to obtain the most suitable X-ray images. Therefore, mammography causes not only physical burden but also psychological distress [6] [7]. The physical burden associated with mammography has been assessed by several subjective and objective methods [8]-[13]. As the subjective method, visual analogue scale (VAS) [14] and McGill pain questionnaire (MPQ) [15] were used to predict the pain during mammography [8] [9]. Objective criteria such as muscle activities [10] [11], electrical stimulation [12] and pupil sizes [13] were related with physical burden during mammography. Psychological distress during mammography has been also investigated by assessing autonomic nervous system function related with heart rate variability (HRV) [16]. According to this investigation, the sympathetic nerve was active not only during mammography but also before mammography, and moreover, sympathetic activity before mammography was the most dominant. It meant that women undergoing mammography were under stress and they were most stressful when they were waiting to undergo mammography in particular.

Several investigators have then reported as to the alleviation of pain and distress associated with mammography [17] [18] [19] [20] [21]. Patient-controlled compression was tested as a method to alleviate pain [17]. With this method, one of the breasts was compressed by a radiographer and the other was compressed by the participant. In $71 \%$ of the participants, self-compression resulted in significantly less pain than compression by a radiographer without a difference in the adequacy of the image quality and compression of the breast. The usefulness of radiolucent cushions in the pain alleviation during mammography was demonstrated [18] [19]. However, their use is debatable because of the high cost since these cushions are single-use. For the alleviation of pain and anxiety associated with mammography, effects of listening to a relaxation audiotape before and during mammography were examined [20]. As a result, they did not reduce subjective reports of anxiety or pain. On the other hand, watching funny video during mammography was effective to relieve the pain [21]. More feasible schemes for the alleviation of distresses associated with mammography should be developed.

Recently, some investigations suggested that a pet robot provided the human with a good effect, e.g., reduction of stress hormones [22] [23], improvement of brain functioning [24], and positive psychological effects in social relationships [25] [26]. A communication robot is further expected to engender mental effects, such as pleasure and relaxation [27]. Actually, the proportion of the participants in whom effects on pleasure and relaxing could be recognized tended to be higher in the communication robot group relative to those in the control robot group [28]. Considering these findings, the communication robot may yield successful effects on the alleviation of distress associated with mammography. Therefore, this study aimed to explore effects of the communication robot on dis- 
tress reduction in mammography.

\section{Materials and Methods}

We used HRV to estimate the amount of distress associated with mammography. HRV is the coefficient of variation of the interval between $\mathrm{R}$ wave peaks on an electrocardiogram (ECG), and is a tool that represents the balance between the sympathetic and parasympathetic branches of the autonomic nervous system [29]. Frequency domain analysis was utilized for the variation in the R-R interval of the ECG. Low-frequency (LF: $0.04-0.15 \mathrm{~Hz}$ ) components and high-frequency (HF: $0.16-0.42 \mathrm{~Hz}$ ) components were obtained from the analyzed power spectrum. HF component reflects parasympathetic nerve activity, which is dominant at rest or a relaxed state. On the other hand, LF/HF is associated with sympathetic activity which is dominant at action or a tense state. In addition, heart rate (HR) is influenced by autonomic nervous activity related respiration and circulation and it fluctuates periodically. Thus, HR was also observed in this study. In short, we adopted and measured HR, LF and LF/HF as autonomic nervous indices. As an ECG device, we used Activetracer (GMS Co. AC-301A). This device is able to measure and record $\mathrm{HR}, \mathrm{HF}$ and $\mathrm{LF} / \mathrm{HF}$ at regular time intervals.

Experimental design is shown in Figure 1. Volunteers for this study were recruited through poster advertisements in School of Health Sciences, Niigata University. There were approximately 500 students in the institution. About $75 \%$ of them were female. Nineteen healthy women ( $21-23$ years of age) who contacted us were enrolled in this study. They were students at departments of nursing or radiological technology. All of them had not previously experienced mammography. The participants were given an explanation of the study objectives, methods, and safety, and their informed consent was obtained. This study was conducted from Aug. to Dec. in 2015 with the approval of the Research Ethics Committee of School of Medicine, Niigata University.

The participants were randomly assigned to either an experimental group or a control group. Ten participants were designated as the control group. The other nine participants were designated as the experimental group and talked with a communication robot before mammography (Figure 2). As the communication robot, we used PALRO (FUJISOFT Inc., Tokyo, Japan), which was a chatty, comforting

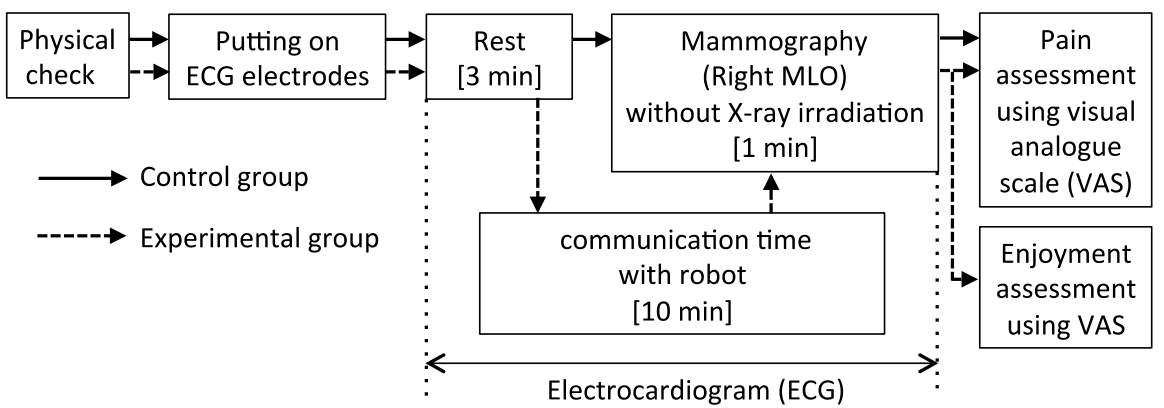

Figure 1. Experimental design. Participants were randomised to either the experimental group or the control group. 


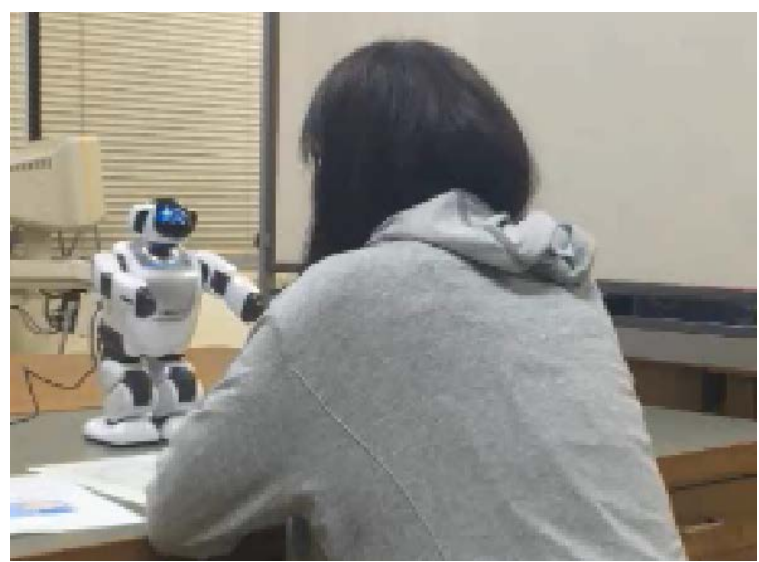

Figure 2. Communication robot PALRO with a participant.

robot. PALRO can communicate with the human and has several specific applications such as dancing, singing and shiritori. The shiritori is a Japanese wordchain game. A list of conversation keywords necessary to communicate with PALRO was prepared. Examples of the keywords are shown in Figure 3. Each of the participants who belonged to the experimental group referred to the list to communicate with PALRO. They talked and played freely with PALRO for ten min before mammography.

EEG data was obtained throughout the experiment that consisted of three min rest phase, ten min communication phase and one min mammography phase. The participants underwent mammography for only medio-lateral oblique (MLO) view of right breast without X-ray irradiation. The degree of pain during mammography was assessed using a VAS immediately after the examination. The experimental group further responded to the VAS for assessment of enjoyment associated with communication with PALRO, and besides, they filled in a questionnaire. The VAS designed for this study is shown in Figure 4. Contents of the questionnaire will be shown in next "Results" section.

\section{Results}

Figure 5 illustrates three time-series graphs of mean HR, mean HF and mean $\mathrm{LF} / \mathrm{HF}$ of the experimental and the control groups. In the experimental group, HR hardly fluctuated during communication with PALRO [Figure 5(a)]. On the other hand, HF decreased gently and LF/HF fluctuated widely during communication with PALRO [Figure 5(b) and Figure 5(c)].

Figure 6 shows three bar charts of mean values of HR, HF and LF/HF in each phase, namely rest phase, communication (comm.) phase and mammography (MMG) phase. The differences in HR, HF and LF/HF between rest phase and mammography phase were statistically significant, respectively $(\mathrm{p}<0.01)$. However, on the differences of HR, HF and LF/HR between rest phase and mammography phase, there were no significant differences between the experimental group and the control group.

Figure 7 indicates mean $\mathrm{HF}$ and mean LF/HF of the experimental group. In 
Greeting \& Introduction

\begin{tabular}{|c|c|}
\hline Communication word & PALRO's behavior \\
\hline Nice to meet you & \multirow[t]{9}{*}{ PALRO greets } \\
\hline Good morning & \\
\hline Good afternoon & \\
\hline Good evening & \\
\hline Good night & \\
\hline Thank you & \\
\hline Excuse me & \\
\hline See you later & \\
\hline I'm home & \\
\hline What's your name? & PALRO says the registered name [default:"PALRO"] \\
\hline When's your birthday? & PALRO says the date he have booted up \\
\hline Introduce yourself & PALRO introduces himself \\
\hline Shake hands with me & PALRO says hello and shakes hands \\
\hline
\end{tabular}

Explanation of function and status

\begin{tabular}{|l|l|}
\hline Communication word & PALRO's behavior \\
\hline $\begin{array}{l}\text { What can you do? } \\
\text { How should I say? }\end{array}$ & PALRO tells us what he can do \\
\hline What should I do? & PALRO proposes a function he has \\
\hline What're you doing? & PALRO's behavior depends on the situation \\
\hline Tell me your ability & PALRO tells us about his ability \\
\hline Today what happened? & PALRO tells us today's news \\
\hline
\end{tabular}

Figure 3. Examples of communication words for PALRO (actually Japanese only) [PALRO user manual:

http://www.palrogarden.net/palro/main/_userdata/PALRO_usermanual_ALL.pdf].

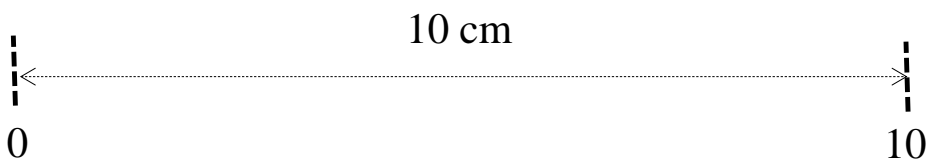

Pain

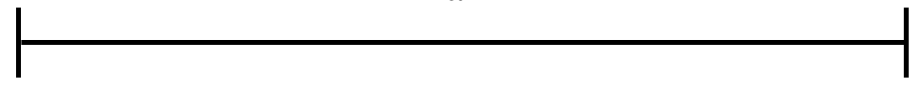

no pain

worst possible pain

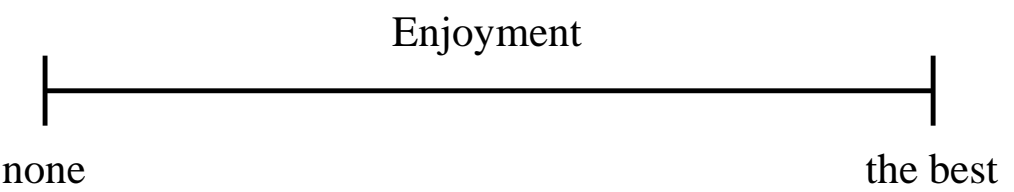

Figure 4. Visual analogue scale designed for this study.

Figure 7, mammography phase was further divided into positioning and breast compression. In particular, $\mathrm{LF} / \mathrm{HF}$ was highest at positioning and suddenly 

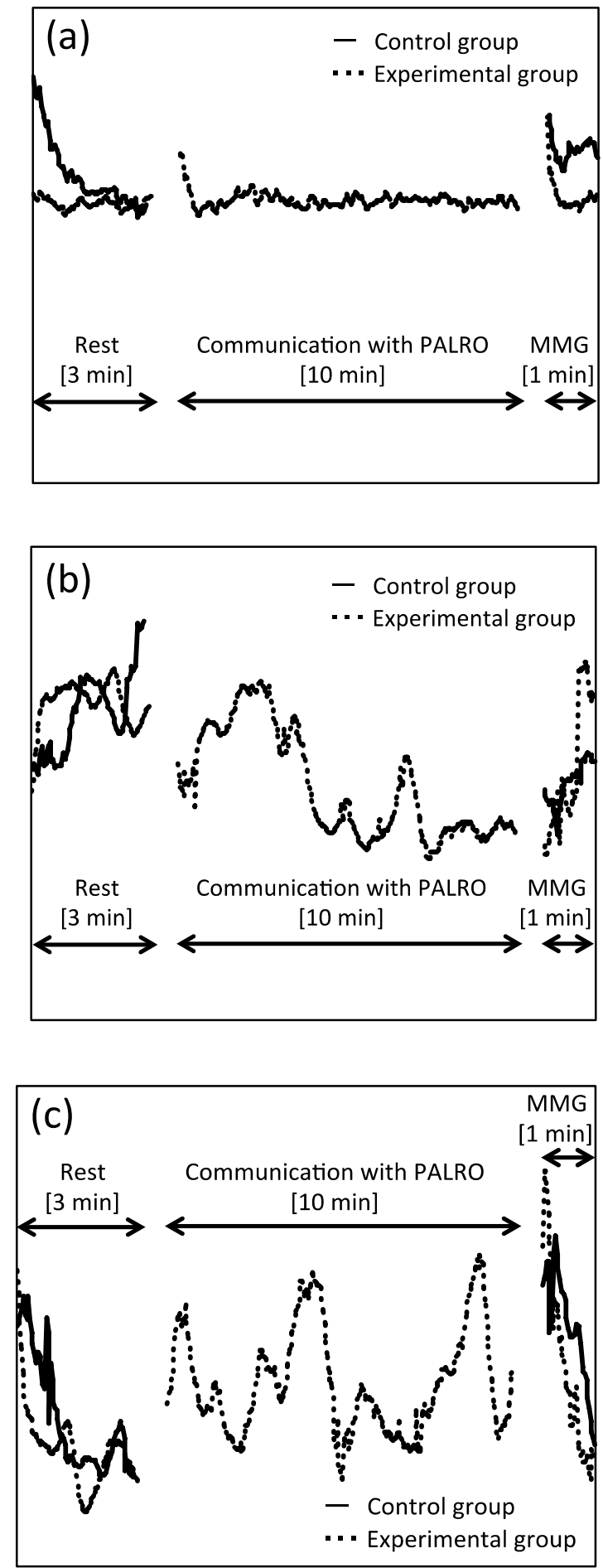

Figure 5. Time-series graphs of autonomic nervous indices. (a) HR, (b) HF, (c) LF/HF. The lines correspond to mean values of all participants' data for each group. MMG is abbreviation of "mammography".

decreased at breast compression.

Mean VAS scores for pain and enjoyment were shown in Figure 8. The VAS 

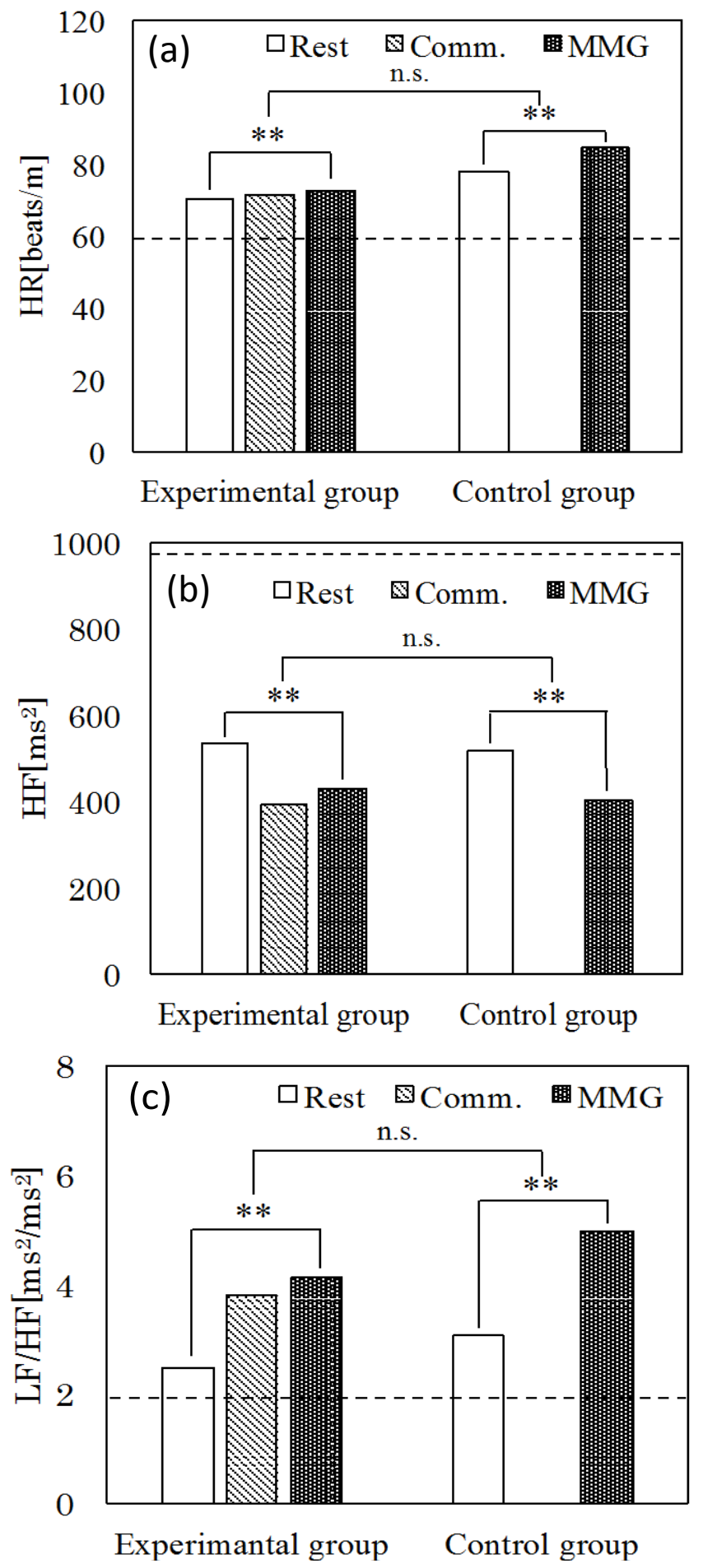

Figure 6. Average values of autonomic nervous indices in each phase. (a) HR, (b) HF, (c) LF/HF. ${ }^{* *}$ : p $<0.01$. The dotted lines indicate normal values of standard measures of HRV (HR: 60 beats/m, HF: $975 \pm 203 \mathrm{~ms}^{2}$, LF/HF: $1.5-2.0$ ). If the obtained HR is larger than the normal value, the subject may not be at a relaxed state at least. If the obtained $\mathrm{HF}$ is larger than the normal value, parasympathetic nerve may be active. If the obtained LF/HF is larger than the normal value, sympathetic nerve may be active. 


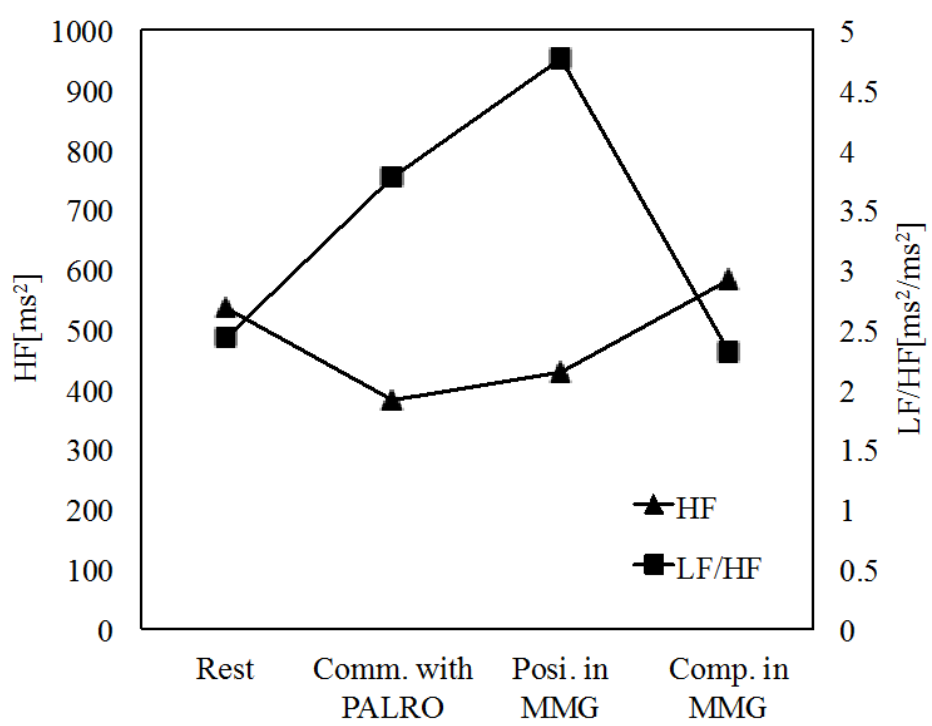

Figure 7. Changes of mean $\mathrm{HF}$ and mean LF/HF in the experimental group. Mammography phase divided into positioning and breast compression.

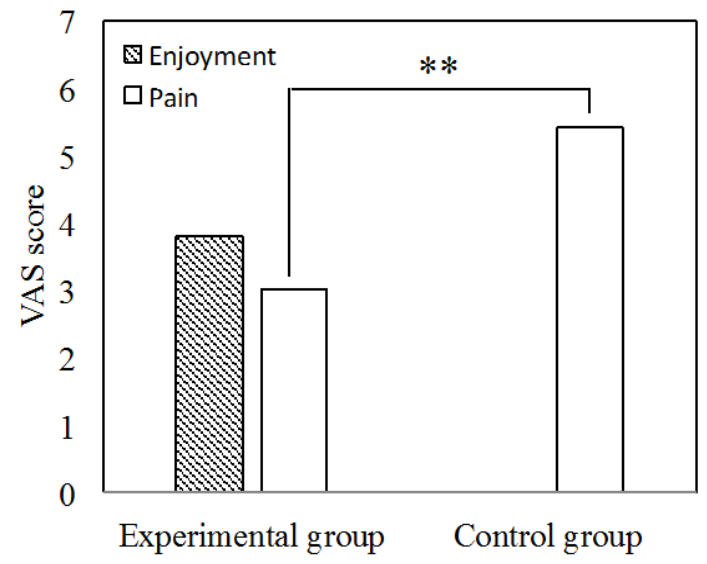

Figure 8. Mean VAS scores for pain and enjoyment. ${ }^{* *}: \mathrm{p}<0.01$.

scores of pain in the experimental group were significantly smaller than ones in the control group $(\mathrm{p}<0.01)$. Table 1 summarizes responses to the questionnaire. Seven out of nine participants in the experimental group felt relaxed during communication with PALRO.

\section{Discussion}

According to Figure 5, parasympathetic nerve activity of both groups was becoming dominant in rest phase, because HF was increasing and LF/HF was decreasing. This meant that all of participants were exactly close to a relaxed state during three min rest. In communication phase, LF/HF fluctuated widely. This may be due to the participant's actions for conversation with PALRO. They were involved in communicating with PALRO. That enthusing must be a cause of fluctuation of LF/HF. When the participants were talking to PALRO, LF/HF 
Table 1. Summary of responses to the questionnaire in the experimental group.

\begin{tabular}{cc}
\hline Question & Response (number of respondent) \\
\hline How did you feel about a ten min for & Short (4) \\
communication with PARLO? & Long (3) \\
& Suitable (2) \\
& Dancing (3) \\
What did you play with PALRO? & Walking (1) \\
& Shiritori (3) \\
& Shake hands (4) \\
What did you feel in the play? & Heard knowledge of various things (4) \\
mid the communication with PALRO & Enjoyed (8) \\
make you relax? & Frustrated (1) \\
& Yes (7) \\
How did you feel about your tension? & No (2) \\
& Rot sure about tension but enjoyed (2) \\
\end{tabular}

would become high. In contrast, when they were paying attention to PALRO's action/talk, LF/HF would become low. According to responses of the questionnaire in Table 1, almost all of them enjoyed the communication with PALRO. Therefore, playing with PALRO would make them excited slightly. That would be why sympathetic activities of them were slightly dominant in communication phase. In mammography phase, we found that participants were in maximum tense state at the beginning of the examination, and their tensions reduced steadily during the examination. Such tendency was similar between the experimental group and the control group.

In Figure 6(a), all values of HR were larger than 60 beats/min that was the standard value of HR at rest in adults [30]. This meant that participants were a little stimulated state. HRs of the control group were larger than ones of the experimental group in both rest and mammography phases. In Figure 6(b), HF values of both groups in all phases were smaller than $975 \pm 203 \mathrm{~ms}^{2}$ that was the normal value of standard measures of HF [29]. This meant that parasympathetic nervous functions were not active, and therefore participants were never a relaxed state. In Figure 6(c), LF/HF values of both groups in all phases were larger than 1.5 - 2.0 that was the normal value of standard measures of LF/HF [29]. This meant that sympathetic nervous functions were active and dominant, and therefore, participants were at action or a tense state. These results implied that mammography examinees would be in a kind of mental distress through the whole examination.

The results of statistical-significance test in Figure 6 indicated that communication with PALRO did not affected autonomic nervous functions during mammography. However, subjective pain degrees by VAS scores were significantly differrent between the experimental group and the control group, as shown in Figure 8. The experimental group was obviously in low level of subjective physical 
pain compared with the control group. This result suggested that communication with PALRO could alleviate a pain associated with mammography. Responses to the questionnaire indicated that the majority participants enjoyed communicating with PALRO and relaxed through it. The enjoyment usually inspires laughs and positive motivations. According to a book on pain relief [31], positive emotions are associated with better outcomes in people with chronic pain with respect to improvements in their ability to cope with pain and in their social functioning [32]. Positive emotions also are associated with better responses to treatment, reduced disability and impairment of physical functioning, and improved health-related quality of life and coping [33] [34]. Some investigators have reported that laughter is good medicine for pain [21] [35]-[40]. The communication with a robot would produce positive emotions with sometimes laughs and it may relieve the pain associated with mammography.

Patients who are going to undergo mammography in a medical institution are usually forced to have waiting time before the examination. The waiting time must enhance the patient's anxieties for mammography [16]. The findings of this study would lead to a wise use of the waiting time. Therefore, the placement of a communication robot in the waiting room or lobby of the medical institution may be recommended in near future.

This study has several limitations. We only employed all the people who contacted us for this study, as the result of our recruitment. The number of subject should further increase for the statistical robustness. An adequate sample size may be determined by power calculation. In this study, we only used PALRO as the communication robot. Recently, several kinds of communication robots except PALRO can be also accessed, such as "Pepper" (Softbank). Using other robot or plural robots may yield more successful knowledge on their effects of distress reduction in mammography. The communication time, ten min in this study, should be optimized to obtain more obvious usefulness of the communication robot on alleviation of anxiety and pain in mammography. These limitations would be overcome in our future work.

\section{Conclusion}

We explored effects of a communication robot on distress reduction in mammography. Autonomic nervous activities were observed before and during mammography. Degrees of subjective pain associated with mammography were also assessed. Unfortunately, the communication robot did not help to intensify parasympathetic nerve activities, which became dominant at rest or a relaxed state. On the other hand, the communication robot was useful for relieving subjective pain associated with mammography. In conclusion, communication with a robot before mammography would yield positive emotions and it would be related to the pain alleviation during mammography.

\section{Acknowledgements}

The authors thank Ms. Yuri Toyoda for assisting with experiments and data analy- 
sis. This study was supported by JSPS KAKENHI Grant Number 26463372.

\section{Conflict of Interest}

The authors declare that they have no conflict of interest.

\section{References}

[1] Jackson, V.P., Lex, A.M. and Smith, D.J. (1988) Patient Discomfort during ScreenFilm Mammography. Radiology, 168, 421-423. https://doi.org/10.1148/radiology.168.2.3393659

[2] Aro, A.R., Absetz-Ylöstalo, P., Eerola, T., Pamilo, M. and Lönnqvist, J. (1996) Pain and Discomfort during Mammography. European Journal of Cancer, 32, 16741679. https://doi.org/10.1016/0959-8049(96)00140-2

[3] Keemers-Gels, M.E., Groenendijk, R.P., Van Den Heuvel, J.H., Boetes, C., Peer, P.G. and Wobbes, T.H. (2000) Pain Experienced by Women Attending Breast Cancer Screening. Breast Cancer Research and Treatment, 60, 235-240. https://doi.org/10.1023/A:1006457520996

[4] Asghari, A. and Nicholas, M.K. (2004) Pain during Mammography: The Role of Coping Strategies. Pain, 108, 170-179. https://doi.org/10.1016/j.pain.2003.12.022

[5] Davey, B. (2007) Pain during Mammography: Possible Risk Factors and Ways to Alleviate Pain. Radiography, 13, 229-234. https://doi.org/10.1016/j.radi.2006.03.001

[6] Montgomery, M. and McCrone, S.H. (2010) Psychological Distress Associated with the Diagnostic Phase for Suspected Breast Cancer: Systematic Review. Journal of Advanced Nursing, 66, 2372-2390. https://doi.org/10.1111/j.1365-2648.2010.05439.x

[7] Whelehan, P., Evans, A., Wells, M. and MacGillivray, S. (2013) The Effect of Mammography Pain on Repeat Participation in Breast Cancer Screening: A Systematic Review. The Breast, 22, 389-394. https://doi.org/10.1016/j.breast.2013.03.003

[8] Hafslund, B. (2000) Mammography and the Experience of Pain and Anxiety. Radiography, 6, 269-272. https://doi.org/10.1053/radi.2000.0281

[9] Sharp, P.C., Michielutte, R., Freimanis, R., Cunningham, L., Spangler, J. and Burnette, V. (2003) Reported Pain Following Mammography Screening. Archives of Internal Medicine, 163, 833-836. https://doi.org/10.1001/archinte.163.7.833

[10] Uchiyama, M., Lee, Y., Sadakata, M., Sayama, M. and Tsai, D.Y. (2012) Measurement of Muscle Activities for Evaluating Physical Burden and Pain during Mammography Positioning. Tohoku Journal of Experimental Medicine, 228, 53-58. https://doi.org/10.1620/tjem.228.53

[11] Uchiyama, M., Lee, Y., Sadakata, M., Tsai, D.Y. and Sayama, M. (2015) Quantification of the Pain and Physical Burden Experienced during Positioning for Craniocaudal Imaging in Mammography, Evaluated by Measurement of Muscle Activity. Health, 7, 23-34. https://doi.org/10.4236/health.2015.71004

[12] Uchiyama, M., Lee, Y., Shimizu, U. and Saitoh, R. (2015) Quantitative Analysis of Pain during Mammography Using Electrical Stimulation. Open Journal of Nursing, 5, 784-789. https://doi.org/10.4236/ojn.2015.59082

[13] Lee, Y., Uchiyama, M. and Sumiyoshi, T. (2015) Pupil Size Measurement and Sucrose Ingestion for Quantifying and Decreasing Burden of Women during Mammography. Journal of Biomedical Science and Engineering, 8, 700-706. https://doi.org/10.4236/jbise.2015.810067

[14] Keel, K.D. (1948) The Pain Chart. The Lancet, 252, 6-8. 
https://doi.org/10.1016/S0140-6736(48)91787-5

[15] Merzack, R. (1975) The McGill Pain Questionnaire: Major Properties and Scoring Methods. Pain, 1, 277-299. https://doi.org/10.1016/0304-3959(75)90044-5

[16] Uchiyama, M., Lee, Y., Sadakata, M., Kazama, K., Minagawa, Y. and Tsurumaki, M. (2013) Effects of Mammography Positioning on the Autonomic Nervous Function. Health, 5, 1335-1341. https://doi.org/10.4236/health.2013.58181

[17] Kornguth, P.J., Rimer, B.K., Conaway, M.R., Sullivan, D.C., Catoe, K.E., Stout, A.L. and Brackett, J.S. (1993) Impact of Patient-Controlled Compression on the Mammography Experience. Radiology, 186, 99-102. https://doi.org/10.1148/radiology.186.1.8416595

[18] Tabar, L., Lebovic, G.S., Hermann, G.D., Kaufman, C.S., Alexander, C. and Sayre, J. (2004) Clinical Assessment of a Radiolucent Cushion for Mammography. Acta Radiologica, 45, 154-158.

[19] Markle, L., Roux, S. and Sayre, J.W. (2004) Reduction of Discomfort during Mammography Utilizing a Radiolucent Cushioning Pad. The Breast Journal, 10, 345-349. https://doi.org/10.1111/j.1075-122X.2004.21352.x

[20] Domar, A.D., Eyvazzadeh, A., Allen, S., Roman, K., Wolf, R., Orav, J., Albright, N. and Baum, J. (2005)Relaxation Techniques for Reducing Pain and Anxiety during Screening Mammography. American Journal of Roentgenology, 184, 445-447. https://doi.org/10.2214/ajr.184.2.01840445

[21] Lee, Y. and Uchiyama, M. (2015) The Effect of Humorous Stimuli on Alleviating Pain during Mammography: A Preliminary Study. Health, 7, 659-664. https://doi.org/10.4236/health.2015.76078

[22] Wada, K. and Shibata, T. (2006) Living with Seal Robots in a Care House-Evaluations of Social and Physiological Influences. 2006 IEEE/RSJ International Conference on Intelligent Robots and Systems, Beijing, 9-15 October 2006, 4940-4945. https://doi.org/10.1109/iros.2006.282455

[23] Suga, K., Sato, M., Yonezawa, H., Naga, S., Shimizu, J. and Morita, C. (2002) Change in the Concentration of Salivary IgA by Contact of Elderly Subjects with a Pet Robot. Journal of Analytical Bio-Science, 25, 251-254.

[24] Wada, K., Shibata, T., Musha, T. and Kimura, S. (2005) Effects of Robot Therapy for Demented Patients Evaluated by EEG. 2005 IEEE/RSJ International Conference on Intelligent Robots and Systems, Edmonton, 2-6 August 2005, 1552-1557.

https://doi.org/10.1109/IROS.2005.1545304

[25] Shibata, T. and Wada, K. (2011) Robot therapy: A New Approach for Mental Healthcare of the Elderly-A Mini-Review. Gerontology, 57, 378-386. https://doi.org/10.1159/000319015

[26] Robinson, H., Macdonald, B., Kerse, N. and Broadbent, E. (2013) The Psychosocial Effects of a Companion Robot: A Randomized Controlled Trial. Journal of the American Medical Directors Association, 14, 661-667. https://doi.org/10.1016/j.jamda.2013.02.007

[27] Wada, K., Shibata, T., Musha, T. and Kimura, S. (2008) Robot Therapy for Elders Affected by Dementia. IEEE Engineering in Medicine and Biology Magazine, 27, 53-60. https://doi.org/10.1109/MEMB.2008.919496

[28] Tanaka, M., Ishii, A., Yamano, E., Ogikubo, H., Okazaki, M., Kamimura, K., Konishi, Y., Emoto, S. and Watanabe, Y. (2012) Effect of a Human-Type Communication Robot on Cognitive Function in Elderly Women Living Alone. Medical Science Monitor, 18, CR550-CR557. https://doi.org/10.12659/msm.883350

[29] Task Force of the European Society of Cardiology and the North American Society of Pacing and Electrophysiology (1996) Heart Rate Variability: Standards of Mea- 
surement, Physiological Interpretation, and Clinical Use. Circulation, 93, 10431065. https://doi.org/10.1161/01.CIR.93.5.1043

[30] Mason, J.W., Ramseth, D.J., Chanter, D.O., Moon, T.E., Goodman, D.B. and Mendzelevski, B. (2007) Electrocardiographic Reference Ranges Derived from 79,743 Ambulatory Subjects. Journal of Electrocardiology, 40, 228-234. https://doi.org/10.1016/j.jelectrocard.2006.09.003

[31] Institute of Medicine Committee on Advancing Pain Research, Care and Education (2011) Relieving Pain in America: A Blueprint for Transforming Prevention, Care, Education, and Research. National Academies Press, Washington DC, 40-41.

[32] Park, S.H. and Sonty, N. (2010) Positive Affect Mediates the Relationship between Pain-Related Coping Efficacy and Interference in Social Functioning. The Journal of Pain, 11, 1267-1273. https://doi.org/10.1016/j.jpain.2010.02.023

[33] Fisher, M.N., Snih, S.A., Ostir, G.V. and Goodwin, J.S. (2004) Positive Affect and Disability among Older Mexican Americans with Arthritis. Arthritis Care \& Research, 51, 34-39. https://doi.org/10.1002/art.20079

[34] Karoly, P. and Ruehlman, L.S. (2006) Psychological Resilience and Its Correlates in Chronic Pain: Findings from a National Community Sample. Pain, 123, 90-97. https://doi.org/10.1016/j.pain.2006.02.014

[35] Martin, R.A. (2001) Humor, Laughter, and Physical Health: Methodological Issues and Research Findings. Psychological Bulletin, 127, 504-519. https://doi.org/10.1037/0033-2909.127.4.504

[36] Mora-Ripoll, R. (2010) The Therapeutic Value of Laughter in Medicine. Alternative Therapies in Health and Medicine, 16, 56-64.

[37] Adams, E.R. and McGuire, F.A. (1986) Is Laughter the Best Medicine? A Study of the Effects of Humor on Perceived Pain and Affect. Activities, Adaptation and Aging, 8, 157-175. https://doi.org/10.1300/J016v08n03_17

[38] Rotton, J. and Shats, M. (1996) Effects of State Humor, Expectancies, and Choice on Postsurgical Mood and Self-Medication: A Field Experiment. Journal of Applied Social Psychology, 26, 1775-1794. https://doi.org/10.1111/j.1559-1816.1996.tb00097.x

[39] Nove, O., Keinan, G. and Teshimovssky, A.M. (1993) Humor and Pain Tolerance. Humor. International Journal of Humor Research, 6, 71-88.

[40] Weisenberg, M., Tepper, I. and Schwarzwald, J. (1995) Humor as a Cognitive Technique for Increasing Pain Tolerance. Pain, 63, 207-212.

https://doi.org/10.1016/0304-3959(95)00046-U

\section{Submit or recommend next manuscript to SCIRP and we will provide best service for you:}

Accepting pre-submission inquiries through Email, Facebook, LinkedIn, Twitter, etc. A wide selection of journals (inclusive of 9 subjects, more than 200 journals)

Providing 24-hour high-quality service

User-friendly online submission system

Fair and swift peer-review system

Efficient typesetting and proofreading procedure

Display of the result of downloads and visits, as well as the number of cited articles

Maximum dissemination of your research work

Submit your manuscript at: http://papersubmission.scirp.org/

Or contact jbise@scirp.org 